\title{
Analysis and Experimental Characterization of Low Speed Direct Drive Fractional Slot Concentrated Winding Surface Permanent Magnet Synchronous Motor with Consequent Pole Rotor
}

\begin{abstract}
Shi-Uk Chung ${ }^{\dagger}$, Yon-Do Chun* and Seok-Hwan Moon**
Abstract - This paper describes analysis and experimental characterization of low speed direct drive fractional slot concentrated winding (FSCW) surface permanent magnet synchronous motor (SPMSM) with consequent pole $(\mathrm{CP})$ rotor, for which studies have been recently performed. The proposed motor, which consists of 30 poles and 36 slots, is analyzed and characterized by extensive 2D finite element analysis (FEA) and together with 3D FEA for an appropriate PM overhang length design. The validity of the analysis is confirmed by the corresponding experiments which fully characterize the proposed motor with excellent agreement between the FEA and the experiments. Thermal stability is also experimentally examined to determine continuous operating points and instantaneous operating points of the proposed motor. It is highly expected that the proposed motor is applicable for low speed direct drive applications.
\end{abstract}

Keywords: Consequent pole, Direct drive, Finite element analysis, Fractional slot, Surface permanent magnet synchronous motor

\section{Introduction}

For low speed high torque applications, combination of a motor and a reduction mechanism has been being used for many years. However, this conventional mechanism consists of wear-prone components which cause noise/ vibration, maintenance, and energy conversion loss, etc. Due to the recent advance in power electronics, position sensors and high energy permanent magnet (PM) materials, PM direct drive motors have been gradually expanding their roles in various industries.

By definition, the PM direct drive motor directly transmits energy to load without any intermediate mechanical component and it realizes improved motion dynamics, more precise positioning control and higher efficiency with near-zero maintenance. [1-4].

A fractional slot concentrated winding (FSCW) surface permanent magnet synchronous motor (SPMSM) topology has been considered as the most suitable for low speed direct drive applications due to low torque ripple and short end-turn winding length. In general, this particular type of motor has a large diameter rotor with high number of poles to maximize torque density by reducing magnetic flux path, however, a large amount of rare earth PM is needed.

$\dagger$ Corresponding Author: Electric Motor Research Center, Korea Electrotechnology Research Institute/Department of Energy and Power Conversion Engineering, University of Science \& Technology, Changwon, Korea. (suchung@keri.re.kr)

* Electric Motor Research Center, Korea Electrotechnology Research Institute/Department of Energy and Power Conversion Engineering, University of Science \& Technology, Changwon, Korea.

** Electric Motor Research Center, Korea Electrotechnology Research Institute, Changwon, Korea.

Received: October 23, 2014; Accepted: April 6, 2015
Due to the recent price surge and unstable supply of rare earth materials, FSCW SPMSM with consequent pole (CP) rotor has been introduced and studied to reduce the amount of rare earth PM. It is reported that it can realize high number of poles, high torque density and low torque ripple which are typically required for low speed direct drive applications. However, to remove magnetic unbalance caused by CP rotor, a special pole-slot combination and winding connection are required $[5,6]$. To avoid magnetic leakage problem which is also caused by $\mathrm{CP}$ rotor, mechanical components of non-magnetic material has to be carefully implemented $[7,8]$.

This paper describes analytic and experimental characterization of a 30pole-36slot FSCW SPMSM with $\mathrm{CP}$ rotor based on the previous studies. This paper performs extensive 2D finite element analysis (FEA) for the theoretical characterization and 3D FEA to determine an appropriate PM overhang length to compensate output torque loss, which can be possibly caused in a thin profile motor. For the effective reduction of cogging torque and torque ripple, an appropriate skew angle is chosen through step skew modeling technique combined with 2D FEA [9]. A prototype is fabricated based on the analysis, the validity of the analysis is experimentally verified and thermal behavior of the prototype is also experimentally examined to ensure continuous operation points.

\section{FEA Characterization of Proposed Motor}

Fig. 1 shows the geometry of $1 / 3$ cycle model of the proposed motor, which is almost identical to the 


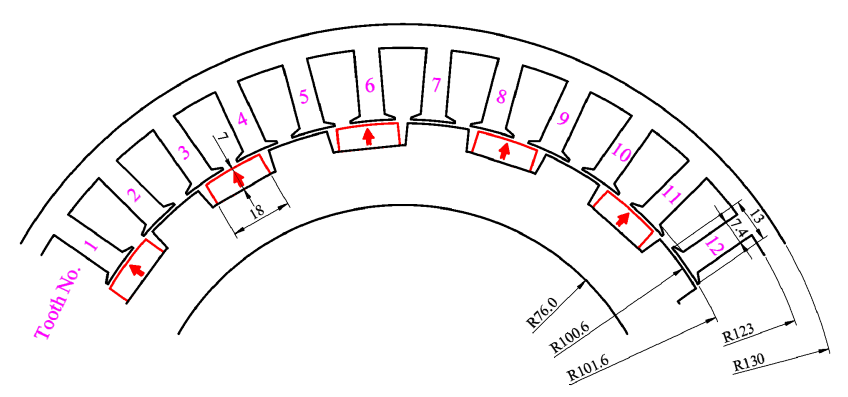

Fig. 1. Dimensions of proposed motor, 1/3 model.

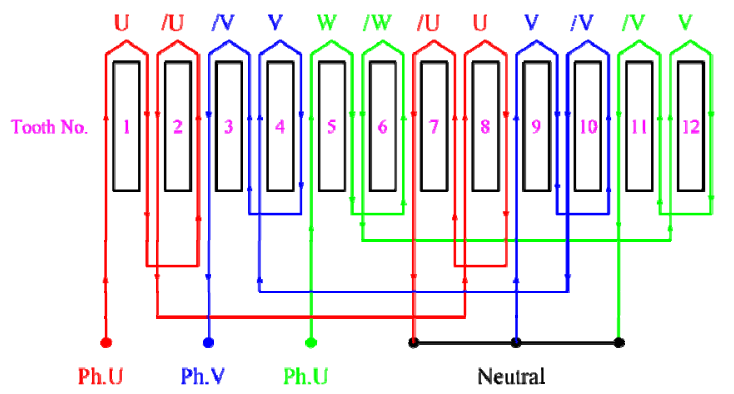

Fig. 2. Proposed motor winding connection, 1/3 model.

Table 1. Proposed motor design specifications

\begin{tabular}{c|c}
\hline Item & Description \\
\hline Rated torque & $40 \mathrm{Nm}$ \\
\hline Rated speed & $600 \mathrm{RPM}$ \\
\hline Number of poles/slots & $30 / 36$ \\
\hline Airgap length & $1.0 \mathrm{~mm}$ \\
\hline Stator stack length & $32.0 \mathrm{~mm}$ \\
\hline Rotor stack length & $38.0 \mathrm{~mm}$ \\
\hline Stator skew & $1 / 3$ pole-pitch $\left(\tau_{\mathrm{p}}\right)$ \\
\hline Stator core & $35 \mathrm{PN} 440, \mathrm{t} 0.35$ \\
\hline Rotor core & $35 \mathrm{PN} 440, \mathrm{t} 0.35$ \\
\hline PM material & $\mathrm{HUNTSMAN}$ \\
\hline & Aradite CW229-3 \\
\hline Encapsulation material & Aradur HW229-1 \\
\hline Copper wire & $0.7 \mathrm{~mm}, \mathrm{Class} \mathrm{F}$ \\
\hline Winding fill factor & $30 \%$ \\
\hline Number of series turns/phase & 384 \\
\hline Parallel connection/phase & 3 \\
\hline Phase resistance & $0.72 \mathrm{Ohm}$ at $20^{\circ} \mathrm{C}$ \\
\hline & \\
\hline &
\end{tabular}

conventional FSCW SPMSM except for CP rotor. To remove magnetic unbalance caused by the $\mathrm{CP}$ rotor, each phase of the proposed motor is composed of 4 series connection as shown in Fig. 2. Table 1 lists the major design specifications of the proposed motor.

Due to the characteristics of the direct drive motor to which load is directly connected, reduction of cogging torque and torque ripple is an important design concern. For the ripple reduction of the proposed motor, step skew modeling technique combined with 2D FEA is performed to consider the skew effect [9]. Especially for a thin profile motor like the proposed one in this paper, it often needs an appropriate PM overhang since the stator stack is merely $32 \mathrm{~mm}$, which is quite thin when it is compared to the overall size. In the thin profile geometry, it can be observed that a significant difference between 2D FEA results and experimental results. For this reason, 3D FEA is selectively performed in this paper to determine the PM overhang length so that the $2 \mathrm{D}$ and the $3 \mathrm{D}$ FEA results have almost the same rms values in no load induced phase voltage. For the convenience of analysis, the 3D FEA is performed for the relatively simpler geometry without stator skew and its result is compared with the $2 \mathrm{D}$ FEA result in the PM overhang design.

As shown in Fig. 3, the 2D FEA is compared with the 3D FEA with/without PM overhang, respectively. A 6.0 $\mathrm{mm}$ PM overhang is chosen as listed in Table 1 since the rms no load induced phase voltages obtained from the $2 \mathrm{D}$ and the $3 \mathrm{D}$ FEA are practically the same as compared in Fig. 3.

As shown in Fig. 4, from the combination of the number of poles/slots, the period of the cogging torque is $1 / 6$ polepitch $\left(\tau_{p}\right)$ which is corresponding to 30 electrical degrees. Consequently, the skew angle is acceptably good enough to reduce the cogging torque if it is an integer multiple of $1 / 6 \tau_{\mathrm{p}}$. It can be seen that the $1 / 6 \tau_{\mathrm{p}}$ skew and $1 / 3 \tau_{\mathrm{p}}$ skew have the same effect on the cogging torque reduction as mentioned above.

However, under loaded state, output torque ripple is also affected by harmonic components of the no load induced phase voltage since the output torque is the cross product of the no load induced phase voltage and the applied

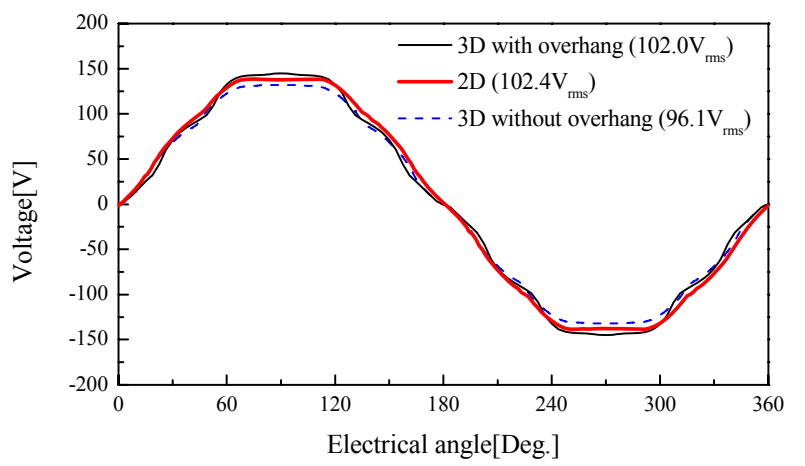

Fig. 3. Comparison of no load induced phase voltages according to PM overhang lengths at 600RPM.

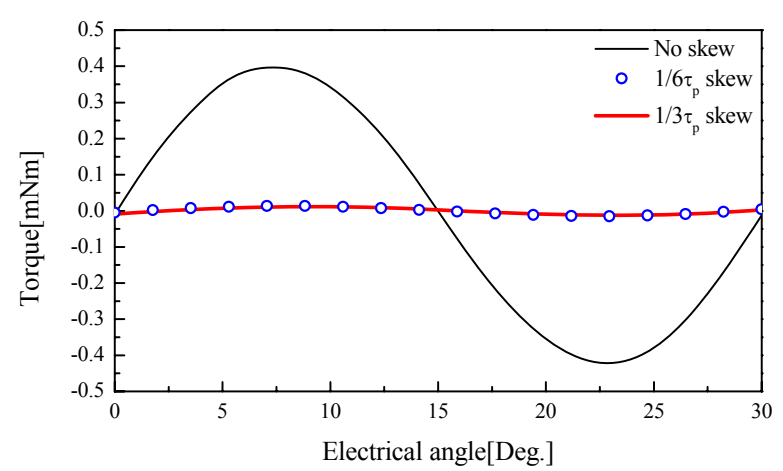

Fig. 4. Comparison of cogging torque waveforms according to stator skew angles. 


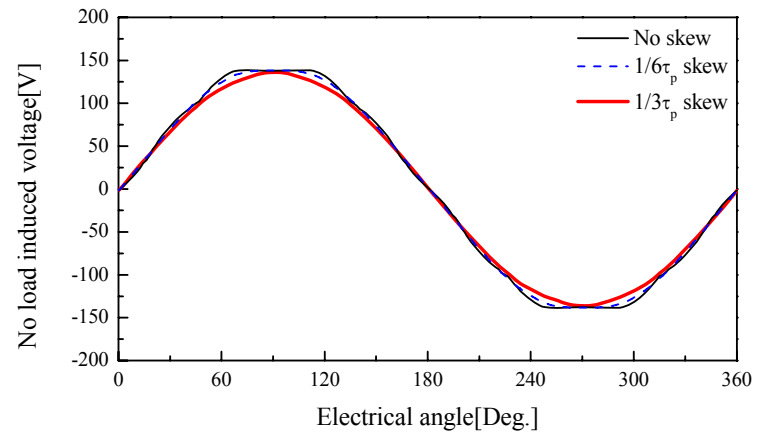

Fig. 5. Comparison of no load induced phase voltage waveforms according to stator skew angles at 600 RPM.

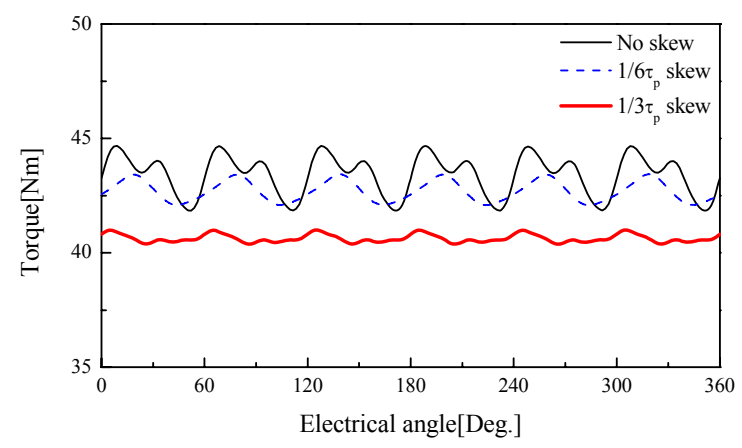

Fig. 6. Comparison of output torque waveforms according to stator skew angles.

Table 2. Comparison of FEA results according to skew angles

\begin{tabular}{c|c|c|c}
\hline Item & No skew & $1 / 6 \tau_{\mathrm{p}}$ skew & $1 / 3 \tau_{\mathrm{p}}$ skew \\
\hline $\begin{array}{c}\text { No load induced phase voltage } \\
\text { at 600RPM [V } \mathrm{V}_{\text {rms }}\end{array}$ & 102.4 & 100.8 & 96.3 \\
\hline $\begin{array}{c}\text { Fundamental voltage at } \\
\text { 600RPM [V] }\end{array}$ & 144.3 & 142.2 & 135.8 \\
\hline THD [\%] & 3.7 & 2.1 & 1.0 \\
\hline Output torque [Nm] & 43.4 & 42.7 & 40.6 \\
\hline Torque ripple [\%] & 6.5 & 3.2 & 1.5 \\
\hline
\end{tabular}

phase current. Therefore, it is desirable to investigate the reduction of the total harmonic distortion (THD) of the no load induced phase voltage together in decision of the skew angle. The no load induced phase voltage waveforms according to skew angles at 600 RPM are compared in Fig. 5 which shows that the better sinusoidal waveform can be achieved by the skew angle of $1 / 3 \tau_{\mathrm{p}}$. Fig. 6 compares the torque waveforms according to the skew angles under the same current loading condition. In this case, it can be also seen that the $1 / 3 \tau_{\mathrm{p}}$ skew is more effective than the $1 / 6 \tau_{\mathrm{p}}$ skew in reduction of the torque ripple. Table 2 shows the numerical comparison of the no load induced phase voltage, total harmonic distortion, rated torque and torque ripple for each case, respectively. It can be concluded that the skew angle of $1 / 3 \tau_{\mathrm{p}}$ is a reasonable choice when the ripple reduction at no load and loaded conditions is taken into careful consideration.

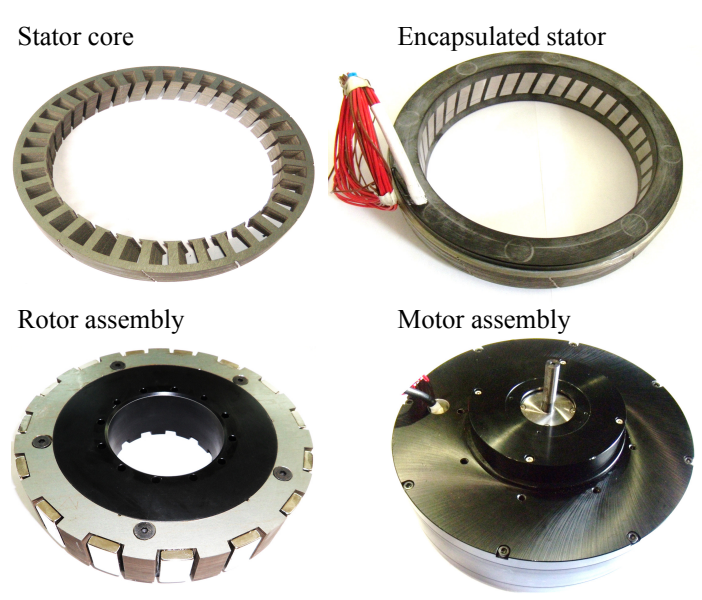

Fig. 7. Prototype

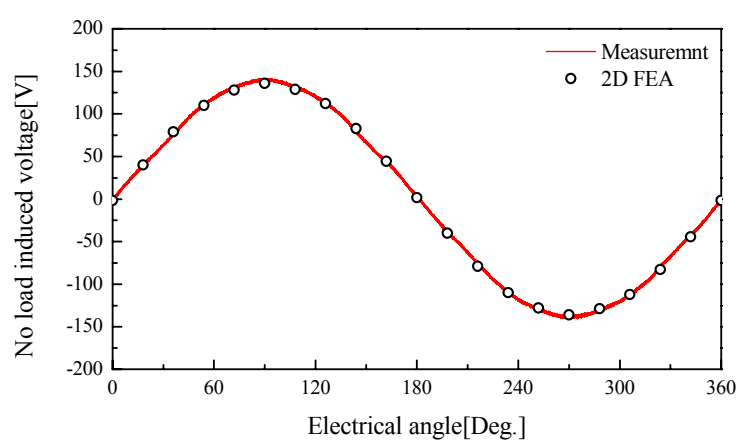

Fig. 8. No load induced phase voltage at 600RPM

\section{Experimental Verification of Analysis and Performance Evaluation}

Based on the analysis, the prototype for the experimental verification was fabricated as shown in Fig. 7 where the CP rotor structure can be seen on the lower left corner. Fig. 8 compares the no load induced phase voltage waveforms at 600 RPM. It can be seen that the measured no load induced phase voltage matches well with the 2D FEA due to the reasonable PM overhang design determined by the $3 \mathrm{D}$ FEA. Fig. 9 compares current vs. torque characteristics obtained by the 2D FEA and the experiments, showing good linearity of up to $300 \%$ of the design-rated torque.

It is arguable, but generally, accepted that near-zero maintenance is one of the advantages of direct drive motors. However, lifespan and continuous output power are closely related to winding temperature. Therefore, thermal characteristics of direct drive motor has to be examined with care.

A typical direct torque motor is subject to frequent acceleration and deceleration. In other words, it needs to operate from continuous operating region to instantaneous operating region frequently without any electrical, mechanical, and thermal damage. Therefore, stator encapsulation, which securely puts stator core and windings together, is often preferred in many direct drive motors 


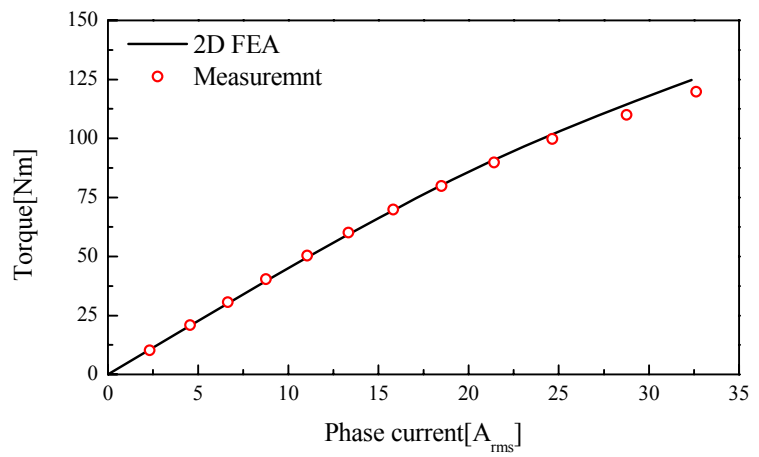

Fig. 9. Comparison of current vs. torque characteristics.

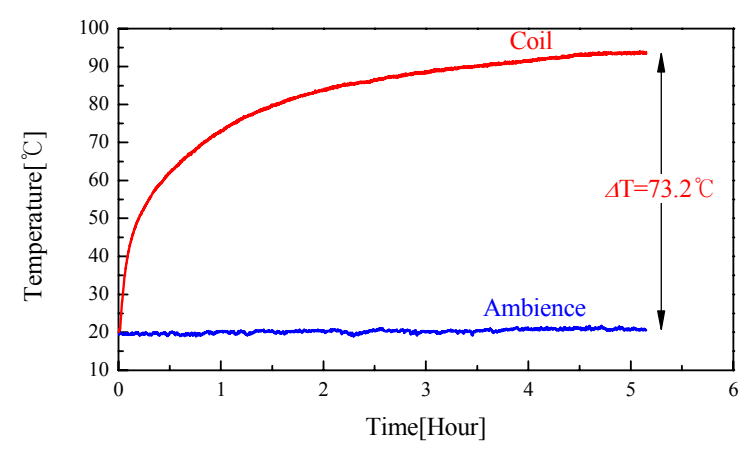

Fig. 10. Measurement of winding temperature rise.

since this kind of motor has to withstand mechanical and thermal loading with near-zero maintenance. It should be noted that the encapsulation also provides thermal conduction path from the winding to the stator core and other mechanical parts which face the ambient air. For this reason, the stator assembly of the prototype was encapsulated with epoxy resin as shown in Fig. 7.

The maximum winding temperature rise was measured for more than 5 hours under the continuous operation at $38 \mathrm{Nm}$ and 600RPM as shown in Fig. 10 which shows the temperature rise was approximately 73 degrees under the natural cooling condition at the ambient temperature of about $20^{\circ} \mathrm{C}$. It was experimentally examined that the prototype is thermally stable under the given continuous load condition mentioned above since the insulation class of the winding is $\mathrm{F}$.

However, it is observed that the prototype needs $3 \%$ more of phase current to generate $38 \mathrm{Nm}$ at $600 \mathrm{RPM}$ when compared with the data shown in Fig. 9 due mainly to $\mathrm{PM}$ temperature rise. Considering the $\mathrm{PM}$ temperature coefficient which is $-0.10 \% /{ }^{\circ} \mathrm{C}$, the estimated $\mathrm{PM}$ temperature rise is around 30 degrees.

Fig. 11 shows the measured efficiency map covering the whole operating range of the prototype. It can be seen that the maximum efficiency reaches up to $90 \%$ at the designrated operating point, $40 \mathrm{Nm}$ and 600RPM. Considering the thermal characteristics of the prototype, the efficiency map can be divided into the instantaneous operation region and the continuous operation region which are shown also in Fig. 11.

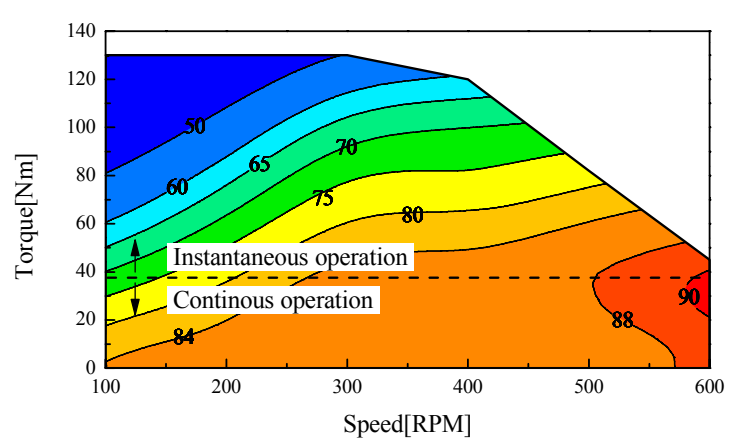

Fig. 11. Measured efficiency map.

\section{Conclusion}

This paper proposed and characterized an FSCW SPMSM with CP rotor for low speed direct drive applications. For the theoretical characterization of the proposed motor, extensive 2D FEA was carried out in the magnetic field computation together with 3D FEA for the PM overhang length design. The validity of the analysis was carefully examined and confirmed by the corresponding experiments which showed excellent agreement. The thermal behavior of the proposed motor was also experimentally investigated to ensure the continuous operating region in the efficiency map. It was confirmed by the experiment that the maximum efficiency over $90 \%$ can be achievable at the design-rated output power of $40 \mathrm{Nm}$ and 600RPM.

With all the general characteristics shown both analytically and experimentally, the proposed topology can be of interest in low speed direct drive applications since it offers sinusoidal no load induced phase voltage, low cogging torque, low torque ripple, good current vs. torque linearity up to $300 \%$ of the rated torque, and high efficiency as well as good thermal stability under the continuous operation at the rated state.

Noting that the CP rotor geometry which increases saliency, the proposed topology can be possibly applied for electric vehicle traction. Maximum torque per ampere control and field weakening capability will be further investigated in the future.

\section{Acknowledgment}

This work was supported by the Energy Efficiency \& Resources of the Korea Institute of Energy Technology Evaluation and Planning(KETEP) grant funded by the Korea government Ministry of Knowledge Economy (No. 20122010100130).

\section{References}

[1] R. Wrobel, and P. H. Mellor, "Design Considerations of a Direct Drive Brushless Machine With Con- 
centrated Windings," IEEE Trans. Energy Convers., vol. 23, no. 1, pp. 1-8, Mar. 2008.

[2] Z.Q. Zhu, "Fractional slot permanent magnet brushless machines and drives for electric and hybrid propulsion systems," in Proc. EVER'2009, Monaco, Mar. 26-29, 2009. [Online]. Available: http://cmrt. centrale-marseille.fr/cpi/ever09/ever2009/conference. html

[3] A. M. El-Refaie, "Fractional-Slot ConcentratedWindings Synchronous Permanent Magnet Machines: Opportunities and Challenges," IEEE Trans. Ind. Electron., vol.57, no.1, pp. 107-121, Jan. 2010.

[4] T. M. Jahns, "The expanding role of PM machines in direct-drive applications," in Proc. 2011 Intl. Conference on Electrical Machines and Systems (ICEMS' 2011), pp. 1-6, Beijing, China, Aug. 2011.

[5] S. U. Chung et al., "Fractional Slot Concentrated Winding Permanent Magnet Synchronous Machine With Consequent Pole Rotor for Low Speed Direct Drive," IEEE Trans. Magn., pp. 2965-2968, Nov. 2012.

[6] S. U. Chung, J. W. Kim, Y. D. Chun, B. C. Woo, and D. K. Hong, "Fractional Slot Concentrated Winding PMSM With Consequent Pole Rotor for a Low-Speed Direct Drive: Reduction of Rare Earth Permanent Magnet," IEEE Trans. Energy Convers., vol. 30, no. 1 pp. 103-109, 2015.

[7] S. U. Chung, J. W. Kim, B. C. Woo, D. K. Hong, J. Y. Lee, and D. H. Koo, "A novel design of modular three-phase permanent magnet vernier machine with consequent pole rotor," IEEE Trans. Magn., vol. 47, no. 10 pp. 4215-4218, Oct. 2011.

[8] S. U. Chung, Y. D. Chun, B. C. Woo, D. K. Hong, and J. Y. Lee, "Design considerations and validation of permanent magnet vernier machine with consequent pole rotor for low speed servo applications," J. Electr. Eng. Technol., vol. 8, no. 5, pp. 742-747, Sept. 2013.

[9] S. Williamson, T. J. Flack and F. Volschenk "Representation of skew in time-stepped two-dimensional finite element models of electrical machines," IEEE Trans. Ind. Appl., vol. 31, no. 5, pp. 1009-1015, Sep./ Oct. 1995.

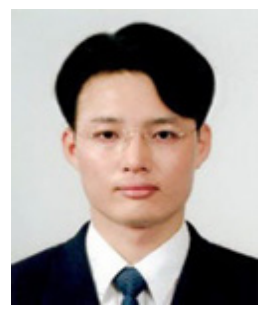

Shi-Uk Chung received the B.S., M.S., and $\mathrm{Ph} . \mathrm{D}$. degrees in mechanical engineering from Pusan National University, Busan, South Korea, in 1997, 1999, and 2010, respectively. From 2002 to 2005, he was with Samick THK, Daegu, South Korea, as a Researcher. Since 2005, he has been with the Electric Motor Research Center, Korea Electrotechnology Research Institute, Changwon, South Korea, as a Senior Researcher. His research interests include the design and analysis of linear and rotary direct drive electric machines.

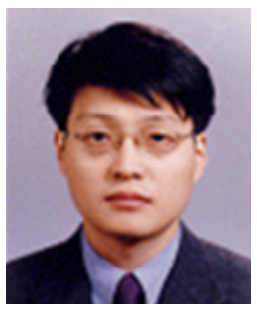

Yon-Do Chun received the B.S., M.S. and $\mathrm{Ph} . \mathrm{D}$. degrees in electrical engineering from Hanyang University, Seoul, South Korea, in 1996, 1998 and 2001, respectively. From 2001 to 2003, he received a Japan Society for the Promotion of Science (JSPS) fellowship and he was with the Department of Electrical Engineering at Waseda University as a visiting scholar. From 2004 to 2011, he was with the Mechatronics Research Group, Korea Electrotechnology Research Institute, Changwon, South Korea, as a Senior Researcher. Since 2012, he has been with the Electric Motors Research Center as a Principal Researcher and Technical Leader. His research interests include the design and analysis of industrial induction machines, permanent-magnet machines and high torque machines.

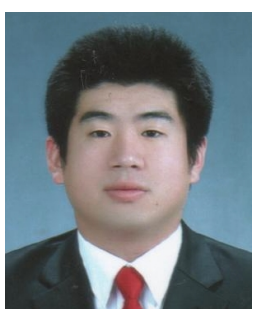

Seok-Hwan Moon received the B.S. degree in electrical engineering from Dong-A University, Busan, South Korea in 2011, and the M.S. degree in mechanical engineering from Pusan National University, Busan, South Korea, in 2014. Since 2011, he has been with the Electric Motor Research Center, Korea Electrotechnology Research Institute Changwon, South Korea as a Researcher. His research interests include the control of electrical machines, and renewable energy. 